\title{
Hyperprolactinaemia causes and manifestation in outpatient practice
}

\author{
Lina Zabuliene ${ }^{1,2,6}$, Modesta Petraviciute ${ }^{3}$, Birute Pauliukiene ${ }^{2}$,
} Airida Audrone Bagdziuniene ${ }^{4}$, Jurgita Urboniene ${ }^{5}$

${ }^{1}$ Clinics of Rheumatology, Traumatology - Orthopaedics and Reconstructive Surgery, Faculty of Medicine, Vilnius University, Vilnius, Lithuania; ${ }^{2}$ Antakalnio outpatient clinic, Vilnius, Lithuania; ${ }^{3}$ Faculty of Medicine, Vilnius University, Vilnius, Lithuania; ${ }^{4}$ Centre of Endocrinology, Vilnius University Hospital Santariskiu Klinikos, Vilnius, Lithuania; ${ }^{5}$ nfectious Diseases and Tuberculosis Hospital, Vilnius University hospital Santariskiu klinikos, Vilnius, Lithuania; ${ }^{6}$ Karoliniskiu outpatient clinic, Vilnius, Lithuania.

\section{INTRODUCTION}

Hyperprolactinaemia is a common endocrine disorder. In the general population rate of hyperprolactinaemia reaches up to $3 \%$. In young women with secondary amenorrhea its prevalence varies from $5 \%$ to $14 \%$, depending on age and manifestation [1-6]. Causes are related to physiological factors, renal and liver failure, hypothyroidism, autoimmune disorders, prolactinoma and other pathological conditions. There are a wide variety of drugs that can induce a significant hyperprolactinaemia frequently associated with clinical symptoms. Prolactinomas are the most common hormone-secreting pituitary tumours [1-11]. Women with prolactinoma present with clinical manifestations of galactorrhoea, primary or secondary amenorrhea or irregular cycles, delayed menarche, infertility, body weight gain, the presence of a pituitary tumour may cause visual-field defects or headache [1-9]. The condition causes systemic complaints that often resolve when the prolactin level returns to normal or once the tumour shrinks [1-6].

\section{OBJECTIVE}

The aim of the study was to analyse clinical manifestation of hyperprolactinaemia in routine clinical practice.

\section{MATERIAL AND METHODS}

We conducted retrospective review of medical records of patients with hyperprolactinaemia (serum prolactin concentration $>1000 \mathrm{mIU} / \mathrm{l}$ ) treated at Vilnius Antakalnio outpatient clinic in 2011-2014. Pregnant and lactating women and patients with macroprolactin were excluded. We recorded demographic data, medical history, body mass index (BMI), LH, FSH, TTH, LT4, anti-TPO concentration and MRI results.

Statistical analysis was performed using software SPSS version 20.0. Categorical variables were reported as numbers and percentages, and continuous variables as mean and SD. The between-group differences were examined with Mann-Whitney $U$ test. For categorical variables the significance of differences among the groups was evaluated with the $x^{2}$ test. The significance level chosen to test statistical hypotheses was 0.05 .

\section{RESULTS}

We analysed data of 68 patients ( $4.4 \%$ male and $95.6 \%$ female). Mean age was $31.60 \pm 9.23$ years. Mean prolactin concentration was $1448.75 \pm 526.78 \mathrm{mlU} / \mathrm{l}$. Patients' characteristics are presented in Table 1.

Table 1. Patients' characteristics

\begin{tabular}{|l|c|}
\hline \multicolumn{1}{|c|}{ Variable } & Mean \pm SD \\
\hline Age, years & $31.60 \pm 9.23$ \\
\hline BMl, kg/m m $^{2}$ & $25.41 \pm 6.43$ \\
\hline Prolactin, $\mathrm{mIU} / \mathrm{I}$ & $1448.75 \pm 526.78$ \\
\hline $\mathrm{LH}, \mathrm{U} / \mathrm{I}$ & $8.98 \pm 4.97$ \\
\hline $\mathrm{FSH}, \mathrm{U} / \mathrm{I}$ & $6.73 \pm 1.92$ \\
\hline $\mathrm{TTH}, \mathrm{mIU} / \mathrm{I}$ & $2.33 \pm 1.83$ \\
\hline LT4, pmol/l & $13.80 \pm 4.65$ \\
\hline anti-TPO, kIU/I & $176.61 \pm 242.36$ \\
\hline
\end{tabular}

Irregular cycles were observed in $48.5 \%$ of women galactorrhoea in $20.6 \%$, and infertility in $20.6 \%$. Headache was present in $17.6 \%$ of patients, body weight gained in $13.2 \%$ of women (Figure 1 ).

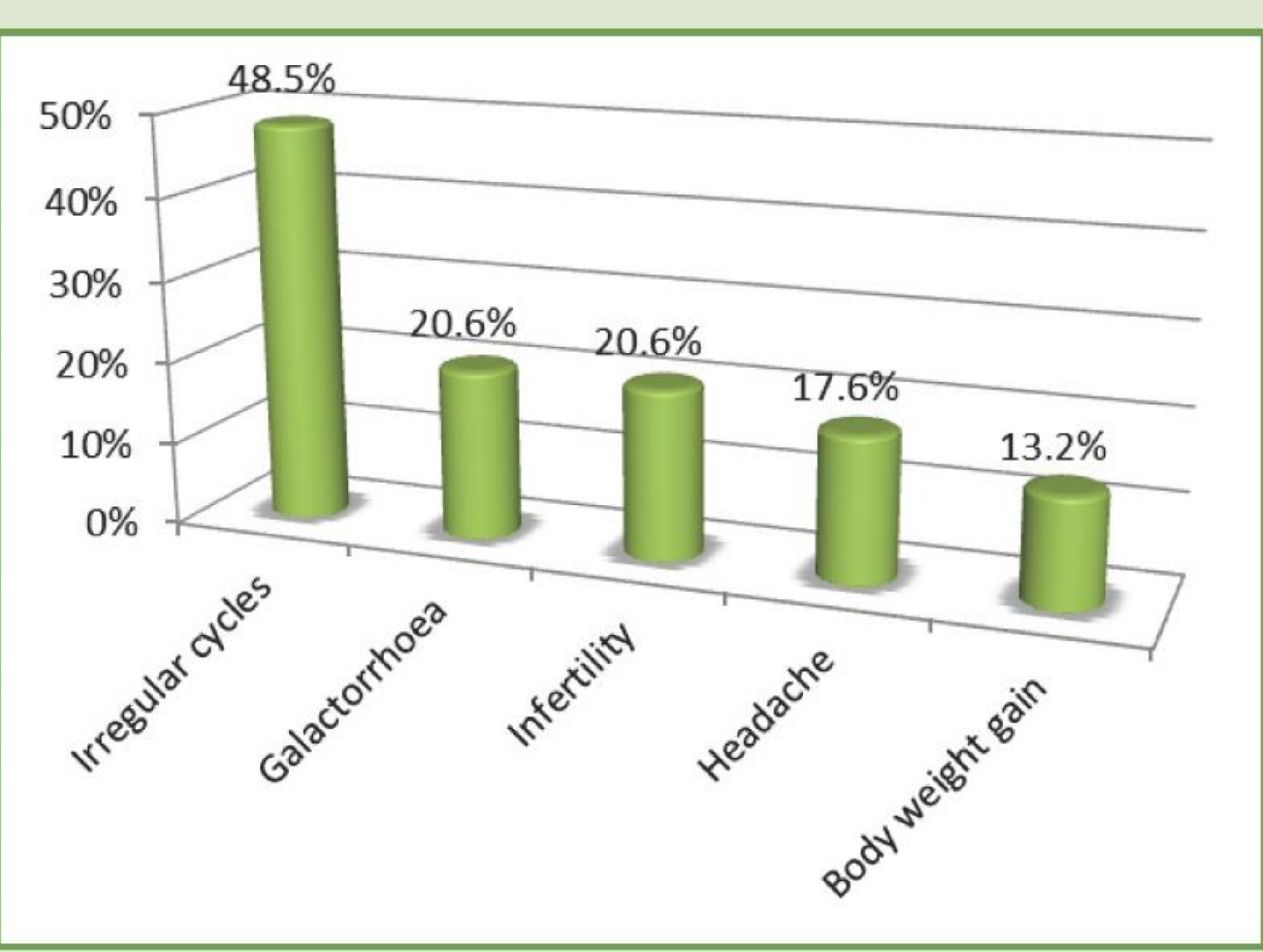

Figure 1. The most frequent complains of patients with hyperprolactinaemia.

The most frequent concomitant diseases were thyroid disorders (41.2\%), mental illnesses, including usage of antidepressants or neuroleptics (14.7\%) and polycystic ovary syndrome (7.4\%).

$50.0 \%$ of the patients underwent MRI: pituitary microadenoma was diagnosed in 13 patients, macroadenoma in 2 , empty sella syndrome in 1 and pituitary cyst in 1 . MRI results of 17 patients didn't show any pathology.
Table 2. Comparison of patients with and without pituitary pathology

\begin{tabular}{|l|c|c|c|}
\hline Variable & $\begin{array}{c}\text { Patients with } \\
\text { pituitary } \\
\text { pathology, N=17 }\end{array}$ & $\begin{array}{c}\text { Patients without } \\
\text { pituitary pathology, } \\
\text { N=17 }\end{array}$ & p \\
\hline Age, years & $35.35 \pm 9.41$ & $27.88 \pm 8.14$ & 0.012 \\
\hline $\begin{array}{l}\text { BMl, } \mathrm{kg} / \mathrm{m}^{2} \\
\text { Prolactin, } \\
\mathrm{mlU} / \mathrm{l}\end{array}$ & $25.91 \pm 7.81$ & $23.12 \pm 5.92$ & 0.606 \\
\hline $\mathrm{TTH}, \mathrm{mlU} / \mathrm{l}$ & $2.809 .25 \pm 538.74$ & $1288.41 \pm 281.15$ & 0.375 \\
\hline $\mathrm{LT} 4, \mathrm{pmol} / \mathrm{l}$ & $13.10 \pm 7.64$ & $2.07 \pm 1.17$ & 1 \\
\hline anti-TPO, kIU/I & $176.17 \pm 213.76$ & $27.56 \pm 3.82$ & 1 \\
\hline
\end{tabular}

Patients with pituitary pathology were older than those with normal MRI results $(35.35 \pm 9.41$ vs. $27.88 \pm 8.14$ years, $\mathrm{p}=0.012$ ). There was no difference in prolactin concentration, hormone concentration, BMI, frequency of complains and underlying diseases between groups (Table 2 and Figure 2).

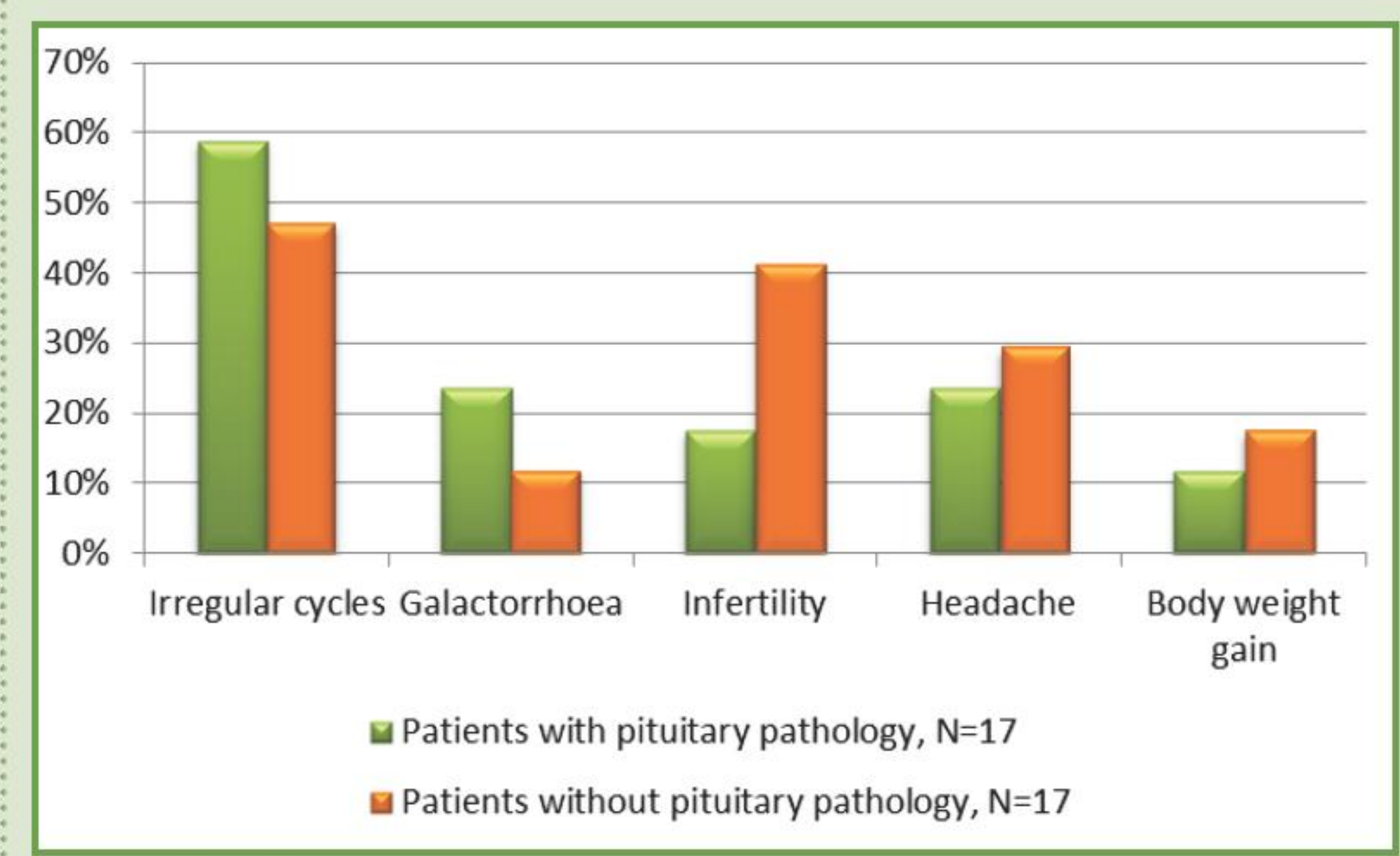

Figure 2. The frequency of complains in groups of patient with and without pituitary pathology.

In a group of patients without pituitary pathology anti-TPO was associated with prolactin level $(r=0.900$, $\mathrm{p}=0.037$ ).

$76.4 \%$ of patients with hyperprolactinaemia were treated with dopamine agonists (bromocriptine or cabergoline).

\section{CONCLUSION}

Main clinical manifestation of hyperprolactinaemia was menstrual irregularity, galactorrhoea and headache. In routine practice up to $50 \%$ of hyperprolactinaemia cases were associated with causes other than pituitary tumours. Samson SL, Hamrahian AH, Ezzat S. American association ofclinicalendocrinologists, american college of endocrinology disease state clinical review: clinical relevance of macroprolactin the absence or presence of true hyperprolactinemia. Endocr Pract 2015; 21(12):1427-35. Wong A, Eloy JA, Couldwell WT, Liu JK. Update on prolactinomas. Part 1: Clinical manifestations and diagnostic challenges. J Clin Neurosci 2015; 22(10):1562-7. Wong A, Eloy JA, Couldwell WT, Liu JK. Update on prolaction Colao A, Savastano S. Medical treatment of prolactinomas. Nat Rev Endocrinol 2011; 7:267-78
Capozzi A, Scambia G, Pontecorvi A, Lello S. Hyperprolactinemia: pathophysiology and therapeutic approach. Gynecol Endocrinol 2015; 31(7):506-10. thyroid disease in prolactinomas than in somatotrophinomas. Growth Horm IGF Res 2016 29:45-9.

EIMiedany YM, Ahmed I, Moustafa H, ElBaddini M. Hyperprolactinemia in Sjogren'ssyndrome a patient subset or a disease manifestation? Joint Bone Spine 2004; 71:203-8.

$18 \mathrm{th}$ European Congress of Endocrinology, 28-31 May 2016, Munich, Germany 